\title{
KOMPOSISI HASIL TANGKAPAN DAN LAJU TANGKAP (CPUE) USAHA PENANGKAPAN PURSE SEINE DI PELABUHAN PERIKANAN NUSANTARA (PPN) PEKALONGAN, JAWA TENGAH
}

\author{
Dian A.N.N. Dewi ${ }^{a, *}$ dan Iqbal Ali Husnia \\ ${ }^{a}$ Fakultas Perikanan dan Ilmu Kelautan,Universitas Diponegoro, Jl. Prof. Soedarto, SH, Tembalang, \\ Semarang, Jawa Tengah 50275, Indonesia \\ *Corresponding Author: dianayunita_nnd@live.undip.ac.id
}

\begin{abstract}
Abstrak
Pelabuhan Perikanan Nusantara (PPN) Pekalongan merupakan "fishing base" dari armada penangkapan purse seine. Ukuran Gross Tonnage (GT) purse seine berkisar 69-125 GT. Tujuan penelitian ini adalah untuk menganalisis komposisi hasil tangkapan purse seine dan laju tangkap (Catch Per Unit Effort atau CPUE) dari armada penangkapan purse seine. Metode penelitian menggunakan metode survei dan data di analisis secara kuantitatif. Analisis dilakukan pada komposisi hasil tangkapan dan laju tangkap purse seine. Data untuk menganalisis komposisi hasil tangkapan adalah data sekunder dari volume hasil tangkapan purse seine di PPN Pekalongan sepanjang tahun 2016. Laju tangkap dihitung menggunakan data sekunder jumlah trip dan total produksi purse seine di PPN Pekalongan tahun 2008 sampai 2016. Variasi jenis tangkapan dominan adalah ikan pelagis kecil, yaitu Layang Deles (Decapterus macrosoma), Layang Benggol (Decapterus russelli), Lemuru (Sardinella lemuru), dan Kembung lelaki (Rastrelliger kanagurta). Setiap bulan terdapat perbedaan dominansi jenis ikan yang tertangkap mulai dari 7 hingga 11 jenis. Layang Deles dominan tertangkap pada bulan Januari, Oktober, November dan Desember. Layang Benggol terbesar tertangkap pada bulan Juni, Juli, Agustus dan September. Lemuru banyak tertangkap pada bulan Februari, April dan Mei. Sedangkan ikan Kembung Lelaki persentase terbesar pada hasil tangkapan di bulan Maret yaitu sebesar $40 \%$. Lokasi daerah penangkapan di area 712 dan 713 WPP NKRI. CPUE purse seine rata-rata per tahun di PPN Pekalongan adalah $18.712 \mathrm{~kg}$ (18,7 ton) per trip untuk masing-masing kapal. Ini menunjukkan bahwa produktivitas penangkapan purse seine masih cukup rendah jika dibandingkan dengan ukuran Gross Tonnage kapal 69 hingga 125 ton.
\end{abstract}

Kata Kunci: Komposisi Tangkapan, Laju Tangkap, PPN Pekalongan, Purse Seine,

\begin{abstract}
Pekalongan fishing port is a fishing base for purse seiners of small pelagic fish in Central Java. Range of fishing fleets Gross Tonnage is 69 to 125 GT. Purse seine was dominant fishing gear with total percentage $84 \%$ from the total fishing gear at Pekalongan fishing port in 2014. The main target of purse seine is shoaling pelagic fish. The objectives of this research were to analyze the catch composition and Catch Per Unit Effort (CPUE) of purse seiners at Pekalongan Fishing Port. The method of this research used survey method. Data analysis with quantitative descriptive method. Analysis conducted on the catch composition and Catch Per Unit Effort of purse seiners. Data to analyze the catch composition was secondary data of purse seiners catches volume in 2016 from January until December. And to calculate the CPUE used secondary data of fishing trips and total production of purse seiners from 2008 to 2016. Variations of dominant type of captured i.e. Shortfin scad, Indian scad, Bali Lemuru, and Indian mackerel. Every month there was different of species dominance caught by the gear ranged from 7 to 11 species. The percentage of each species was Shortfin scad (Decapterus macrosoma) caught dominantly in January, October, November and December. Indian scad (Decapterus russelli) reached the highest percentage in June, July, August and September. Bali Lemuru (Sardinella lemuru) mostly caught in February, April and May. While Indian mackerel (Rastrelliger kanagurta) caught with highest percentage in March (40\%). Location of fishing ground was in Indonesia Fisheries Mangement Area with code 712 and 713. The annual average CPUE of purse seine in Pekalongan Fishing Port was $18,712 \mathrm{~kg}$ or 18.7 metric tonnes per trip for each fleet. This result shows that the
\end{abstract}


productivity of purse seiners was quite low compared with the size of fishing fleet Gross Tonnage 69 up to 125 tons.

Keywords: Catch Compositions, CPUE, Pekalongan Fishing Port, Purse seiners

\section{PENDAHULUAN}

Pelabuhan Perikanan Nusantara (PPN) Pekalongan merupakan "fishing base" dari armada penangkapan purse seine. Ukuran Gross Tonnage (GT) purse seine berkisar antara 69 sampai 125 GT. Purse seine adalah alat tangkap dominan yaitu sebanyak $84 \%$ dari total jumlah alat tangkap di PPN Pekalongan pada tahun 2014. Alat tangkap purse seine merupakan jenis alat tangkap pukat tarik (seine nets) yang dioperasikan dengan menggunakan perahu atau kapal. Pada alat ini dipasang tali kerut (purse lines) sehingga dapat dilingkarkan (surrounding nets) kemudian ditarik dan membentuk kantong (purse). Di Pekalongan alat tangkap purse seine dioperasikan dengan 1 (satu) kapal (one boat operated purse seine). Target penangkapan purse seine adalah ikan pelagis yang bergerombol atau "pelagic shoaling species". Ukuran kapal yang digunakan alat tangkap purse seine di Pekalongan > 60 GT dengan kekuatan mesin $>140$ PK sedangkan untuk ukuran kapal $<60$ GT tergolong alat tangkap mini purse seine [1]. Berdasarkan [2], tentang Jalur Penangkapan Ikan pasal 22 ayat $1 \mathrm{c}$., penggolongan purse seine adalah dengan panjang tali ris (float rope) atas minimal 600 $m$ dan mesh size $\geq 1$ inchi dan ukuran kapal $\geq$ 30 GT - 100 GT. Daerah penangkapan berada pada jalur III ( > 12 mil laut) WPPRI 571, 711, 712, 713, 715, dan 718 .

Penurunan jumlah alat tangkap purse seine di PPN Pekalongan terjadi dari tahun 1998-2014. Pada tahun 1998 tercatat sebanyak 426 armada. Jumlah dalam kisaran 400 armada bertahan hingga tahun 2004 [3]. Dan 149 unit di tahun 2010 dan menjadi 116 pada tahun 2014 [4]. Jumlah unit penangkapan yang mengalami penurunan ini menarik untuk diamati mengenai bagaimana komposisi tangkapan dan juga laju penangkapannya. Sehingga bisa didapatkan informasi lebih lanjut apakah hasil tangkapan masih sesuai dengan target utama dan juga mengenai produktifitas penangkapan dengan menghitung laju penangkapan (Catch per Unit Effort atau CPUE).

Tujuan penelitian ini adalah untuk menganalisis komposisi hasil tangkapan purse seine dan laju tangkap (Catch Per Unit Effort atau CPUE) dari armada penangkapan purse seine di Pelabuhan Perikanan Nusantara Pekalongan.

\section{MATERI DAN METODE}

Metode penelitian menggunakan metode survei. Analisis data dengan metode deskriptif kuantitatif. Analisis dilakukan pada komposisi hasil tangkapan dan laju tangkap purse seine. Data untuk menganalisis komposisi hasil tangkapan adalah data sekunder dari volume hasil tangkapan purse seine di PPN Pekalongan tahun 2016 dari bulan Januari hingga Desember. Sedangkan untuk menghitung laju tangkap (CPUE) menggunakan data sekunder jumlah trip dan total produksi purse seine di PPN Pekalongan tahun 2008 sampai 2016. Komposisi hasil tangkapan dilakukan pengelompokkan hasil tangkapan dari spesies yang dominan tertangkap pada setiap kapal purse seine. Kemudian dijumlahkan per bulan untuk dihitung persentase dari masing-masing species tangkapan. Pengelompokan dibuat dengan penggunaan stratifikasi per bulan (penggolongan hasil tangkapan) agar dapat mengestimasi species hasil tangkapan setiap bulan [5]. Sehingga dari masing-masing bulan dapat diketahui jenis species dominan apa saja yang tertangkap dengan alat tangkap purse seine. Pengukuran CPUE dilakukan berdasarkan formulasi Schaefer (1957) dalam [6] adalah sebagai berikut :

$$
\mathrm{q}=\mathrm{h} / \mathrm{f}
$$

Dimana:

$\mathrm{q}=$ CPUE (kg/trip)

$\mathrm{h}=$ catch atau hasil tangkapan $(\mathrm{kg})$

$\mathrm{f}=$ effort atau penangkapan (trip) 


\section{HASIL DAN PEMBAHASAN}

Spesifikasi Armada Penangkapan Purse Seine di Pelabuhan Perikanan Nusantara Pekalongan

Armada penangkapan purse seine di PPN Pekalongan bisa dikelompokkan menjadi dua kategori yaitu ukuran 60-90 GT dan >90 GT. Kapal terbuat dari kayu dan ada yang campuran kayu dengan fiber. Armada penangkapan purse seine melakukan kegiatan penangkapan dengan lama trip 32 sampai 100 hari. Jumlah ABK 28 hingga 53 orang per kapal. Sedangkan panjang tali ris atas untuk kelompok 60-90 GT antara 400-600 m dan kelompok >90 GT panjangnya $>600 \mathrm{~m}$. Armada purse seine di PPN Pekalongan merupakan armada yang dominan dengan persentase $84 \%$. Sehingga menjadi usaha perikanan penopang utama kegiatan ekonomi di TPI yang terdapat di PPN Pekalongan. Kapal purse seine juga dilengkapi dengan sistem refrigrated sea water (RSW) sebagai pengawet ikan hasil tangkapan di palka.

Tabel 1. Spesifikasi Armada Penangkapan Purse Seine

\begin{tabular}{clll}
\hline No & \multicolumn{1}{c}{ Keterangan } & Kelompok \\
\hline 1. & Spesifikasi Kapal & $60-90 \mathrm{GT}$ & $>90 \mathrm{GT}$ \\
& Panjang (L) & $21,9-24,5 \mathrm{~m}$ & $19,5-27,10 \mathrm{~m}$ \\
& Lebar (B) & $6,65-6,9 \mathrm{~m}$ & $7,8-8,2 \mathrm{~m}$ \\
& Dalam (D) & $1,7-2,3 \mathrm{~m}$ & $2,25-2,95 \mathrm{~m}$ \\
& Kekuatan mesin & $250-300 \mathrm{pk}$ & $280-350 \mathrm{pk}$ \\
& Panjang tali ris & $400-600 \mathrm{~m}$ & $>600 \mathrm{~m}$ \\
2. & Lama trip rata-rata & 56 hari & 58 hari \\
3. & Jumlah ABK rata-rata & 37 orang & 38 orang \\
\hline
\end{tabular}

Sumber : hasil penelitian (2017)

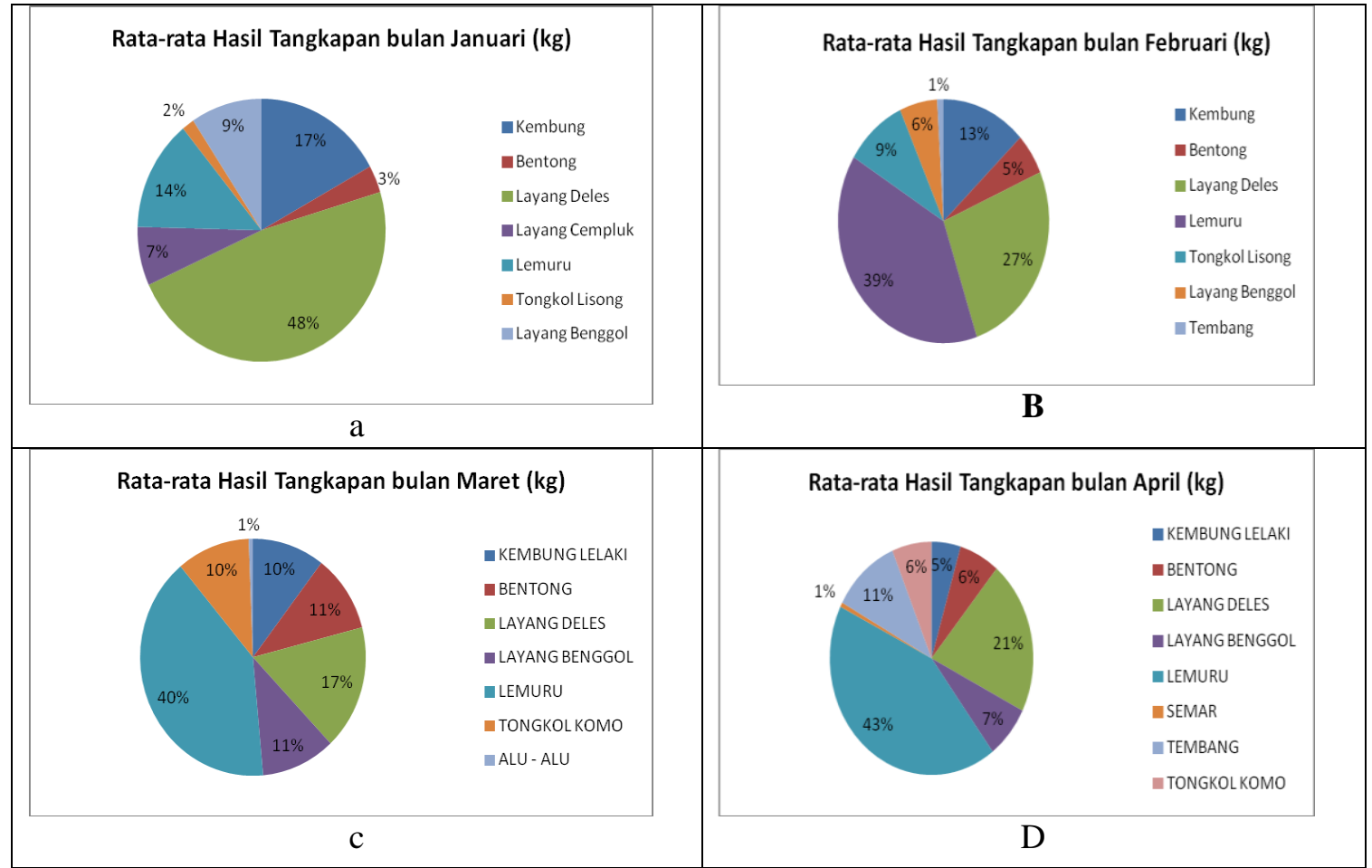

Gambar 1. Rata-rata hasil tangkapan Purse Seine Catur Wulan Pertama Bulan Januari sampai April tahun 2016 

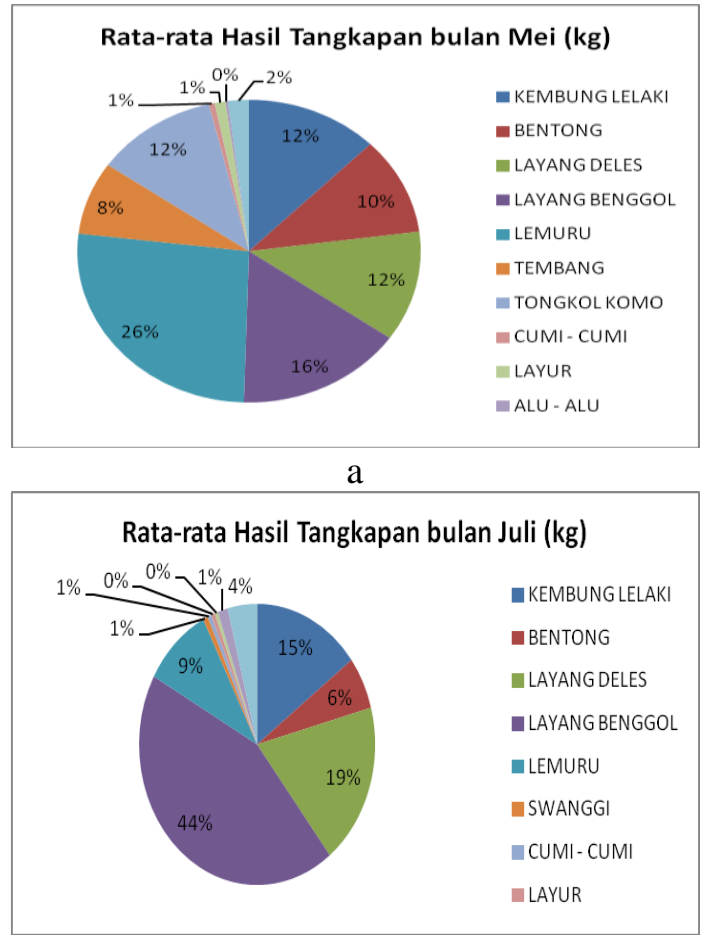

c

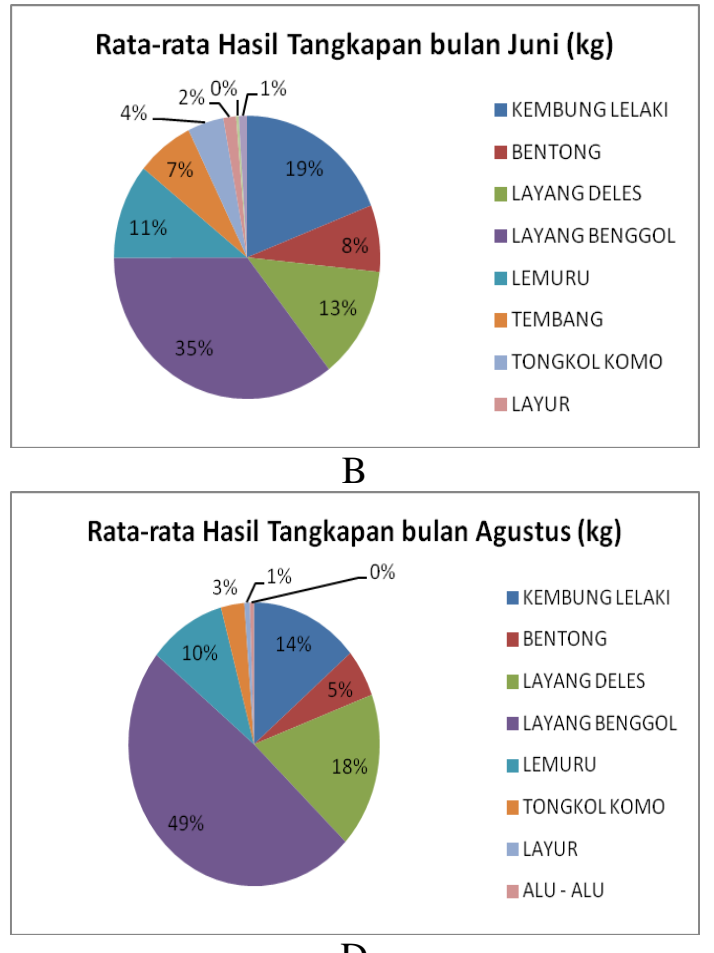

$\mathrm{D}$

Gambar 2. Rata-rata hasil tangkapan Purse Seine Catur Wulan Kedua Bulan Mei sampai Agustus tahun 2016

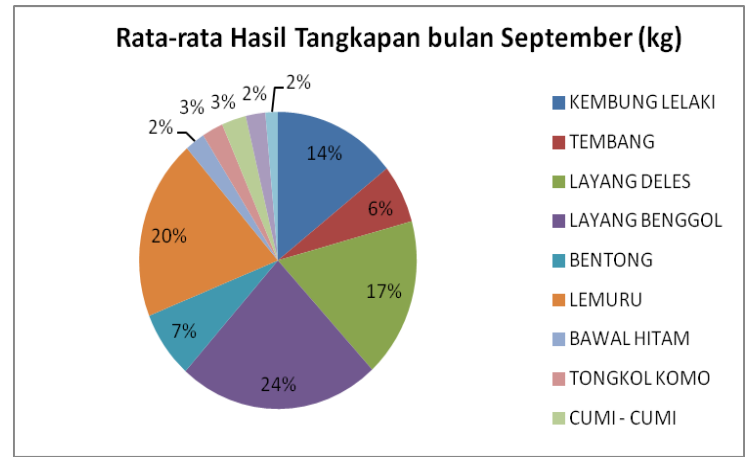

a.

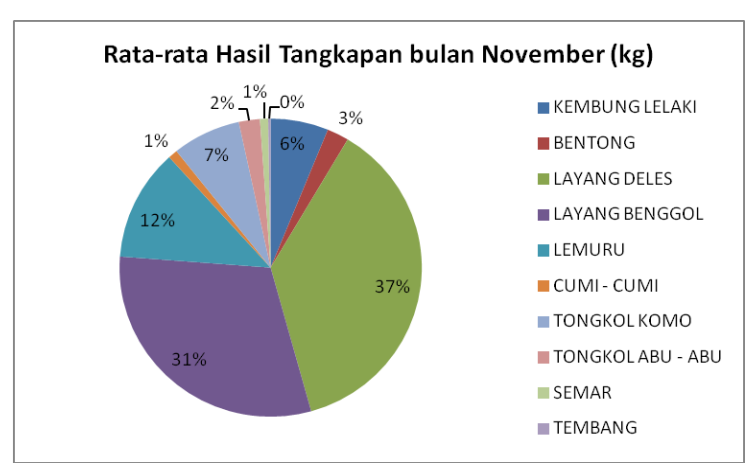

c.

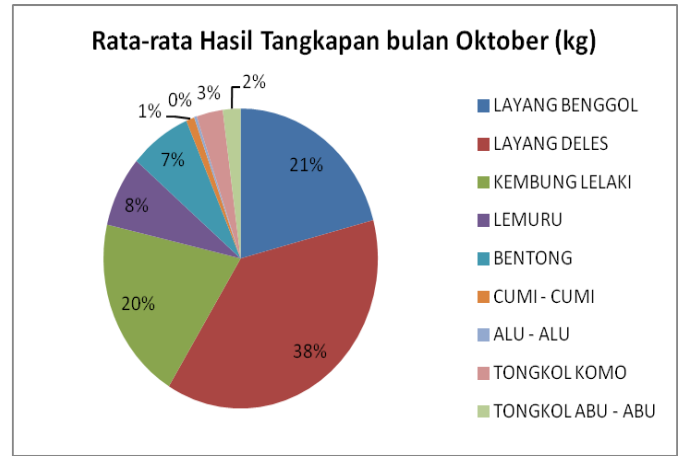

b.



d.

Gambar 3. Rata-rata hasil tangkapan Purse Seine Catur Wulan Ketiga Bulan September sampai Desember tahun 2016 


\section{Komposisi Hasil Tangkapan}

Hasil tangkapan dari alat tangkap purse seine perbulan memiliki komposisi yang beragam. Rata-rata hasil tangkapan setiap bulan dianalisis untuk diketahui komposisi hasil tangkapan dari alat tangkap purse seine. Pada bulan Januari 2016 hasil tangkapan purse seine didominasi oleh ikan layang deles sebanyak $48 \%$ dari total hasil tangkapan. Ada 7 spesies yang menjadi ragam hasil tangkapan yaitu layang deles (Decapterus macrosoma), layang cempluk (Decapterus macarellus), layang benggol (Decapterus russelli), lemuru (Sardinella lemuru), kembung (Rastrelliger kanagurta), bentong (Selar crumenophtalmus), dan tongkol lisong (Auxis rochei). Sedangkan pada bulan Februari, Maret sampai dengan bulan Mei yang paling banyak tertangkap adalah lemuru sebanyak $39 \%$ sampai $43 \%$ dari total hasil tangkapan. Berbeda dengan Januari, pada bulan Februari ikan yang layang yang tertangkap hanya dua jenis yaitu layang benggol dan layang deles.

Data hasil tangkapan purse seine tahun 2016 pada catur wulan pertama yaitu, bulan Januari hingga April menunjukkan perbedaan komposisi jenis tangkapan yang tidak banyak bervariasi. Hasil tangkapan utama adalah lemuru dan layang. Pada bulan Januari komposisi utama hasil tangkapan purse seine adalah layang deles, kembung dan lemuru. Bulan Februari hasil tangkapan yang paling banyak adalah ikan lemuru (39\%), layang deles (27\%) dan kembung (13\%). Sedangkan pada bulan Maret yang tertangkap paling banyak adalah lemuru (40\%), layang deles (17\%) dan bentong sebanyak $11 \%$. Begitu pula pada bulan April, hasil tangkapan juga masih didominasi dengan jenis ikan tersebut. Catur wulan kedua, yaitu bulan Mei, Juni, Juli, dan Agustus hasil tangkapan dominan mulai berubah dari ikan lemuru menjadi ikan layang benggol. Ini ditunjukkan dengan persentase hasil tangkapan yang berkisar antara 35-49\% dari total ikan dominan yang tertangkap dengan alat tangkap purse seine pada catur wulan kedua. Begitu pula pada catur wulan ketiga dari bulan September hingga Desember, ikan pelagis kecil yang paling banyak tertangkap adalah ikan layang benggol dan layang deles. Jumlah variasi hasil tangkapan juga cukup banyak dari 9 hingga 11 jenis species ikan dan molusca. Variasi jumlah species dominan yang tertangkap pad bulan September hingga Desember cukup banyak yaitu ada 9 species hingga 11 species. Bulan September ikan layang benggol tertangkap sebagai species dominan sebesar $24 \%$, sedangkan pada bulan Oktober hingga Desember yang tertangkap sebagai hasil tangkapan dominan adalah ikan layang deles $38 \%, 87 \%$ dan $25 \%$.

\section{Laju Penangkapan Purse Seine di PPN Pekalongan}

Laju penangkapan atau Catch per Unit Effort (CPUE) dihitung guna mengetahui berapa jumlah produksi rata-rata hasil tangkapan untuk setiap unit alat tangkap per trip penangkapan. Dengan total jumlah armada penangkapan pada tahun 2008 hingga 2016 menunjukkan ada fluktuasi armada purse seine di PPN Pekalongan. Hal ini berpengaruh terhadap total produksi hasil tangkapan purse seine per tahun. Dalam penelitian ini dilakukan perhitungan laju penangkapan armada purse seine didapatkan dari membagi total produksi purse seine per tahun dengan total trip penangkapan seluruh alat tangkap purse seine. Hasil perhitungan laju penangkapan dapat dilihat pada (Tabel 2).

Penurunan jumlah trip terjadi dari kurun waktu 2008 hingga 2014. Penurunan berkisar dari $2 \%$ hingga $14 \%$ pada 6 tahun terakhir. Namun pada tahun 2015 hiingga 2016 jumlah trip penangkapan kembali meningkat seiring dengan bertanbahnya jumlah armada penangkapan purse seine. Dampak pada penurunan jumlah trip dan jumlah armada penangkapan adalah menurunnya laju penangkapan Purse Seine di PPN Pekalongan. Namun begitu ada beberapa periode yang menunjukkan peningkatan laju penangkapan yaitu pada periode 2008-2009 dan 2013 2014. Peningkatan CPUE tahun 2008 sampai 2009 sebesar 8\% dan 2013-2014 sebesar 38\%.

Penurunan CPUE tahun 2009-2010 cukup besar yaitu sebesar $79 \%$ yaitu dari 2,3 ton menjadi 1,3 ton. Dan selain periode tersebut juga terdapat penurunan cukup drastis pula 
yaitu pada tahun 2014-2015 sebanyak 55\%. CPUE purse seine rata-rata per tahun di PPN Pekalongan adalah $18.712 \mathrm{~kg}$ atau 18,7 ton per trip untuk masing-masing kapal. Ini menunjukkan bahwa produktivitas penangkapan purse seine masih cukup rendah jika dibandingkan dengan ukuran Gross Tonnage kapal 69 hingga 125 ton.

Tabel 2. Jumlah Armada, Total Trip per tahun dan Produksi per tahun Purse Seine di PPN Pekalongan tahun 2008-2016 [7]

\begin{tabular}{lccc}
\hline Tahun & Jumlah Armada (unit) & Total trip/tahun & Produksi per tahun $(\mathrm{kg})$ \\
\hline 2008 & 152 & 608 & 13.246 .344 \\
2009 & 149 & 596 & 14.203 .741 \\
2010 & 146 & 584 & 7.758 .859 \\
2011 & 136 & 544 & 8.136 .430 \\
2012 & 119 & 476 & 7.539 .900 \\
2013 & 116 & 464 & 7.625 .924 \\
2014 & 116 & 464 & 12.525 .464 \\
2015 & 198 & 792 & 13.822 .000 \\
2016 & 196 & 784 & 13.975 .000 \\
\hline
\end{tabular}

Sumber: Hasil Penelitian yang diolah, 2017

Tabel 3. CPUE Purse Seine dan Total trip per tahun di PPN Pekalongan tahun 2008-2016 [7]

\begin{tabular}{lcc}
\hline Tahun & CPUE (kg/trip) & Trip \\
\hline 2008 & $21.786,75$ & 608 \\
2009 & $23.831,78$ & 596 \\
2010 & $13.285,72$ & 584 \\
2011 & $14.956,67$ & 544 \\
2012 & $15.840,13$ & 476 \\
2013 & $16.435,18$ & 464 \\
2014 & $26.994,53$ & 464 \\
2015 & $17.452,02$ & 792 \\
2016 & $17.825,26$ & 784
\end{tabular}

Sumber: Hasil Penelitian yang diolah, 2017

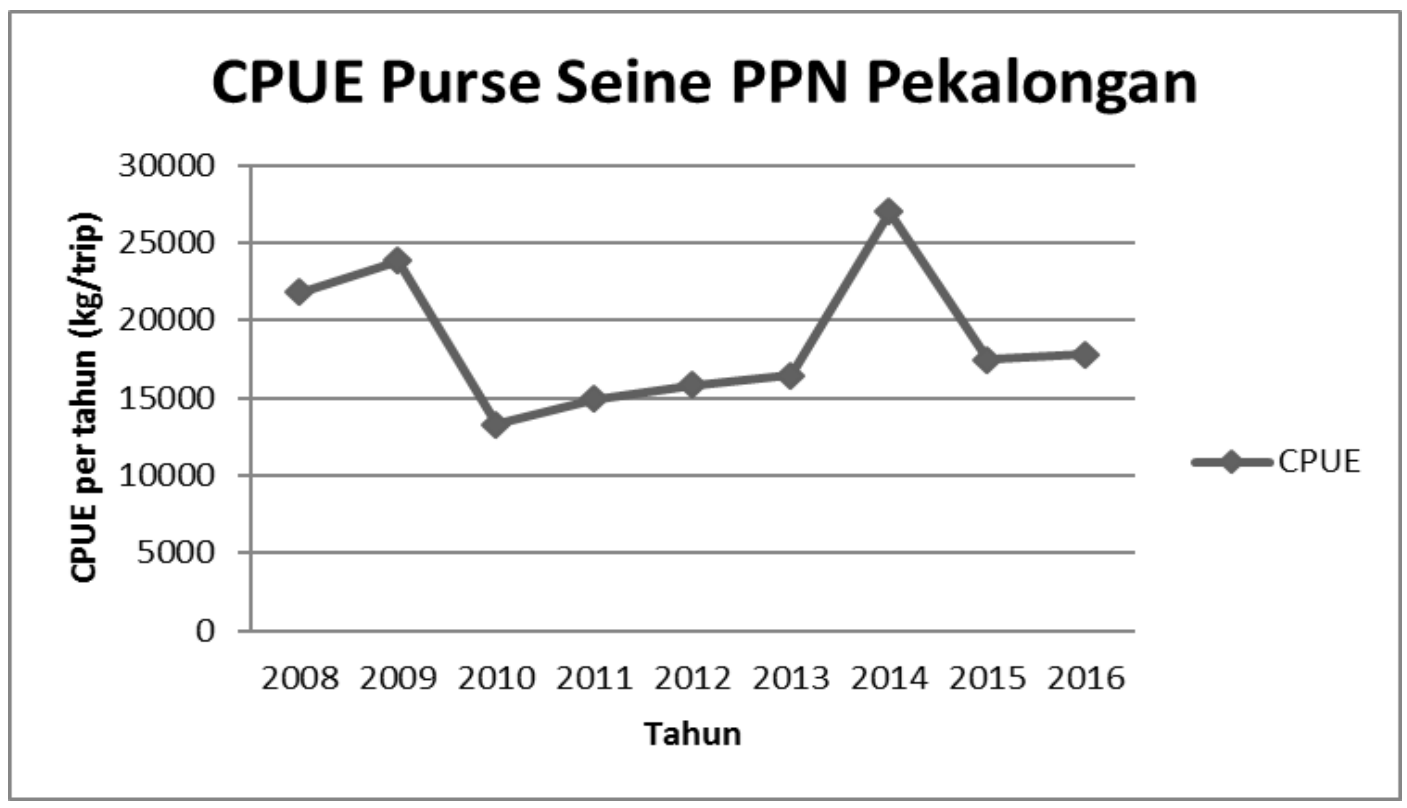


Gambar 4. Fluktuasi CPUE Alat Tangkap Purse Seine di PPN Pekalongan Tahun 2008-2016 [7]

\section{KESIMPULAN}

Berdasarkan hasil penelitian yang dapat disimpulkan adalah

1. Dominansi jenis ikan yang tertangkap oleh armada purse seine adalah ikan pelagis kecil dengan komposisi sebagai berikut: a.Layang Deles (Decapterus macrosoma) b.Layang Benggol (Decapterus russelli) c.Lemuru (Sardinella lemuru) d.Kembung lelaki (Rastrelliger kanagurta)

2. CPUE Rata-rata $18.712 \mathrm{~kg}$ atau 18,7 ton per trip untuk masing-masing kapal. Ini menunjukkan bahwa produktivitas penangkapan purse seine masih cukup rendah jika dibandingkan dengan ukuran Gross Tonnage kapal 69 hingga 125 ton.

\section{UCAPAN TERIMAKASIH}

Penulis mengucapkan terima kasih kepada Fakultas Perikanan dan Ilmu Kelautan Universitas Diponegoro yang telah memberikan bantuan Biaya Penelitian dengan Dana Anggaran PNBP Undip Tahun Anggaran 2017 berdasarkan Surat Perjanjian Pelaksanaan Penelitian FPIK, Undip No. 2291/UN7.3.10/LT/2017. Sehingga penelitian ini dapat dilaksanakan dengan baik. Kepada tim penelitian Himma Galuh N, I. Firdaus, Andika Wiratama, M. F. Hafidz, Indri Putri S, M. Abdul Ghani serta pihak pengelola Pelabuhan Perikanan Nusantara Pekalongan, dan nelayan Purse Seine Pelabuhan Perikanan Nusantara Pekalongan, penulis mengucapkan terima kasih untuk segala bantuannya.

\section{DAFTAR PUSTAKA}

[1] Muhammad, Akbar. 2003. Analisa Kelayakan Usaha dan Efisiensi pada Penggunaan Alat Tangkap Purse Seine di
Kota Pekalongan. (Thesis). Magister Manajemen Sumberdaya Pantai, Universitas Diponegoro.

[2] Peraturan Menteri Kelautan dan Perikanan No. 02 Tahun 2011 tentang Jalur-jalur Penangkapan Ikan.

[3] Sismadi. 2006. Analisis Efisiensi Penggunaan Input Alat Tangkap Purse Seine di Kota Pekalongan (Thesis). Magister Ilmu Ekonomi dan Studi Pembangunan, Universitas Diponegoro, Semarang.

[4] Pelabuhan Perikanan Nusantara Pekalongan. 2014. Jumlah Kapal Perikanan Menurut Jenis Alat Tangkap di Pelabuhan Perikanan Nusantara Pekalongan. PPN Pekalongan.

[5] Walsh, C., R. Bian, J.M. Mackenzie, A. Miller, K. Spong, H. Arminger. 2012. Species Composition and Seasonal Variability in Commercial Purse Seine Catches of Jack Mackerel (Trachurus declivis, T. Murphyi, and $T$. Novaezelandiae) in JMA 1 between January 2009 and September 2011) New Zealand Fisheries Assessment Report 2012/46. Ministry of Primary Industries, New Zealand Government. New Zealand.

[6] Wurlianty, A.H., J. Wenno dan M. E. Kayadoe. 2015. Catch Per Unit Effort (CPUE) Periode Lima Tahunan Perikanan Pukat Cincin di Kota Manado dan Kota Bitung. Jurnal Ilmu dan Teknologi Perikanan Tangkap 2(1): 1-8.

[7] Pelabuhan Perikanan Nusantara Pekalongan. 2016. Data Produksi Bulanan di Pelabuhan Perikanan Nusantara Pekalongan. PPN Pekalongan. 